\title{
Lurzoru kutsatuen karakterizazio intentsiboa in vivo eta in silico fokatzeak erabiliz
}

\author{
(In vivo and in silico approaches for an integral characterization \\ of polluted soils)
}

\author{
Erik Urionabarrenetxea, Nerea Garcia-Velasco, Beñat Zaldibar, \\ Urtzi Izagirre, Manu Soto* \\ Zelulen Biologia Ingurumen Toxikologian (ZBIT) ikerketa taldea, Zoologia \\ eta Animalia Zelulen Biologia Saila, Zientzia eta Teknologia Fakultatea \\ eta Plentziako Itsas Estazioa (PiE-UPV/EHU), \\ Euskal Herriko Unibertsitatea (UPV/EHU), Leioa, Bizkaia
}

\begin{abstract}
LABURPENA: Azken hamarkadetako jarduera antropikoak ekosistemetan desorekak sortzen hasiak dira. Horrela, abeltzaintzak, nekazaritzak eta aktibitate industrialek pestizida eta metalekin kutsaturiko lurzoruen proportzioa emendarazi dute. Kutsatzaileen presentziak, lurzoruetan bizi diren organismoak eta, beraz, lurzoruak eskaintzen dituen Zerbitzu Ekosistemikoak erasatea ekar dezake, arrisku-ebaluazio egokien beharra eskatuz. In silico modeloak, kutsatzaile baten aplikazio osteko ingurumen-kontzentrazioak aurreikusteko tresna egokiak dira, eta substantzien arrisku-ebaluazioan eta -erregulazioan lagundu dezakete. Bestetik, kutsatzaileak lurzoruan duten inpaktua ebaluatze aldera, osasunaren paradigma ikuspuntua; hots, medio naturalak inter-erlazionatutako konpartimentu gisa ulertzen dituena, hedatzen hasi da komunitate zientifikoaren baitan. Era honetan, kutsatzaileek lurzoru organimoetan eragindako efektu toxikologikoen neurketak (in vivo test-ak eta biomarkatzaileak erabiltzen dituztenak) omen handia irabazi dute ingurumenaren osasuna ebaluatzeko orduan. Lan honetan, kutsatutako lurzoruak ebaluatzeko ikuspuntu, teknika, software, gidalerro eta test ezberdinak aurkezten dira; lurzoru-ebaluazio integral bat burutzeko beharrezkoak direnak.
\end{abstract}

HITZ GAKOAK: Kutsatutako lurrak, ecohealth, in silico modeloak, ekotoxikologia, lurzoruko organismoak.

\begin{abstract}
The anthropic activities during the last decade are causing damages on ecosystems. In fact, animal husbandry, agriculture, and industrial activities have increased the proportion of soils contaminated with pesticides and metals. The presence of pollutants could affect soil organisms and the Ecosystem Services provided; thus, a proper risk evaluation is required in order to assess the final environmental impacts of pollutants. In silico models are tools designed to predict environmental concentrations of released pollutants that could assist on substances evaluation and regulation. Meanwhile, the health paradigm, understanding the natural environment as an inter-related compartment, has been spread within the scientific community. Hence, the measurement of toxicological effects produced by contaminants on soil organisms (using in vivo tests and biomarkers) gained a high reputation for evaluating environmental health. This work presents different approaches, techniques, software, guidelines and tests for assessing contaminated soils; crucial for an integrative soil assessment.
\end{abstract}

KEYWORDS: Polluted soils, ecohealth, in silico models, ecotoxicology, soil organisms.

* Harremanetan jartzeko / Corresponding author: Manu Soto. Zientzia eta Teknologia Fakultatea eta Plentziako Itsas Estazioa (PiE-UPV/EHU), Euskal Herriko Unibertsitatea (UPV/EHU) , Leioa, Bizkaia. - manu.soto@ehu.eus - https://orcid.org/0000-00024541-8182

Nola aipatu / How to cite: Urionabarrentetxea, Erik; Garcia-Velasco, Nerea; Zaldibar, Beñat; Izagirre, Urtzi; Soto, Manu (2021). "Lurzoru kutsatuen karakterizazio intentsiboa in vivo eta in silico fokatzeak erabiliz». Ekaia, 41, 2021, 127-149. (https://doi.org/10.1387/ekaia.22785).

Jasotze-data: 2021, maiatzak 3; Onartze-data: 2021, uztailak 22.

ISSN 0214-9753 - elSSN 2444-3581 / (c) 2021 UPV/EHU

(c) (i) $\odot$ Lan hau Creative Commons Aitortu-EzKomertziala-LanEratorririkGabe 4.0 Nazioartekoa

(c) 


\section{SARRERA}

Bigarren Mundu Gerraz geroztik, biztanleria globala esponentzialki hazi egin da, gaur egungo 7.700M-etara iritsi arte [1]. Estimazioen arabera, 2050 urtean, munduko biztanleria 9.7 bilioitara heltzea espero da [2]. Hazkuntza honetarako ezinbestekoak izan ziren, guda handien gabeziaz gain, osasun eta elikaduraren arloan emandako aurrerapausoak. Antiobiotiko eta txertoen aurkikuntzan emandako aurrerapausoek [2], zein ugalketaren arloan lortutakoek, bizi-esperantza 69,11 (1960) urtetatik 83,5 (2018) urtetara hobetzea ahalbidetu izan dute (Espainian); umeen hilkortasuna izugarriki jaisteaz gain (\% 48,4 Europan azken 20 urteetan). Bestalde, nekazaritza-elikagaien industrializazioak janaria kantitate altuetan produzitzea ahalbidetu zuen, neurri batean behintzat desnutrizio- eta gosete-arazoak ezabatuz; aurreko mendeetan sarri izandako arazoak.

Aldiz, aipatutako populazio-hazkuntzak, mendebaldeko gizarteen dogma ekonomiko nagusiarekin batera, non garapena hazkuntza ekonomikoaren baliokide den, baliabide naturalen xahutze etengabea bultzatu dute kultura kontsumista batekin batera. Era berean, ondasunen fabrikazio eta kontsumo etengabeak, hondakin eta emisio desberdinak sortzen dituzte; luzetara, medio lurtar, urtar edo aire konpartimenduan buka ditzaketenak; hauek kaltetuz. Izan ere, azken hamarkadetan gorakada izan duten jarduera antropikoak desoreka handiak sortzen hasiak dira aipatutako ekosistemetan. Horiek horrela, komunitate zientifikoa beste garai geologiko batez hitz egiten hasia da jada: Antropozenoaz. Mundu mailako fenomeno honek, eredu produktibo eta energetikoen gaineko hainbat eztabaida sortu izan ditu, datozen hamarkadetarako ingurumen-erronkak ezarriz.

Iragandako mendean eta oraingoan isuritako berotegi-efektu gasek, atmosferan dauden gasen kontzentrazioa zeharo emendatu du; $\mathrm{CO}_{2}$-aren kasuan, industriaurreko garaitik gaur arteko \% 147ko igoera izan du; 407.8 ppm-ak gaindituz [3]. Gas hauen hazkuntzak lurrazaleko tenperatura gradu batean igotzea ekarri dute jada; eta, iragarpenek diotenez, 2100 urterako igoera hori $4^{\circ} \mathrm{C}-k o a$ izatera hel daiteke [4]. Mundu mailako tenperatura igoerak faunan, floran, gizartean edo ekonomian sor ditzakeen efektuak ezezagunak dira oraindik; hala ere, simulazio ezberdinen eta iragarpen modeloen bitartez posible da (ziurgabetasun jakin batekin) tenperaturaren emendioak sor ditzakeen efektu potentzialak aurreikustea. Beste efektu batzuen artean, berotegi-efektuak lurzoruko materia organikoaren egonkortasuna, karbono-sarreren emendioa (biomasa-produkzio tasa eta deskonposizio-ratioen afekzioagatik), ur-balantzearen asaldatzea edota lurzoru-erabileren aldaketa eragin dezake [5].

Industrializazio azeleratuak, elikagai beharren emendioak edo gero eta ugariagoak diren desplazamendu transozeanikoek metal, pestizida, $\mathrm{PAH}$, zein hidrokarburoen kontzentrazioa areagotzea eragin dute munduko 
ozeano, laku, ibai edo ur-masa ezberdinetan. Era berean, medio urtarra, bizi erabilgarriaren azken atalean dauden makroplastikoen degradaziotik sortutako mikroplastikoen kontzentrazio emendioari aurre egiten ari da. Estimazio ezberdinen arabera, urteko, 5-13 milioi tona plastikok (mundu mailako produkzioaren $\% 1.5$ eta \% 4-ren bitartean) itsasoan bukatzen dute [6], jadanik, puntu batzuetan, 4.000 partikula $/ \mathrm{m}^{3}$-ko kontzentrazioetara iristeraino [7-9]. Era berean, badira lurzoruan mikroplastiko fibra eta zatikatutako mikroplastikoen presentzia baieztatzen dituzten lanak ere [10], batez ere araztegi-lokatzak jaso dituzten nekazal lurretan [11]. Behin mikroplastiko hauek lurrean metatuta, landareek aska ditzakete, kate trofikoan sartzea eta transferitzea ahalbidetuz [12]. Guzti honegatik, plastikoek medio urtar, lurtar edo kate trofikoan sor ditzaketen efektuen gaineko eztabaidak sortu izan dira komunitate zientifikoan.

Bestalde, eraldatu gabeko lurzorua gero eta baliabide urriagoa da. Elikadura eta Nekazaritza Erakundeak (FAO, Food and Agriculture Organization, ingelesez) argitaratu duenez, abeltzaintzan erabiltzen da lurzoru kantitaterik handiena, ingurumena kaltetuz basoen soiltze, lurzoru-erosio, desertifikazio edo biodibertsitate begetalaren galeraren bidez. Gainera, nekazaritzaren hedapenak, habitat naturalen nekazaritza-eremuetarako aldaketak, eta hirien zabaltzeak zeharo areagotu du lurzoru naturalen degradazioa [13]. Horrela, abeltzaintzak, nekazaritzak eta urbanizazio-prozesuek (aktibitate industrialekin batera) fisikoki edo kimikoki kutsaturiko lurzoruen proportzioa zeharo emendarazi dute; lurzoru kutsatuen arazoa globalki hedatutako arazo izendatzera iristeraino $[14,15]$. Izan ere, Ingurumen Agentzia Europarraren (EEA-European Environmental Agency, ingelesez) arabera, 2.5 milioi lursail aurkitu daitezke potentzialki kutsaturik Europar kontinentan; horien artean 340.000 eremu jada kutsatutzat jotzen dira [16].

Lurzorua kutsa dezaketen konposatu eta elementuak bi talde handitan bereizten dira: kutsatsaile organikoak eta inorganikoak [17]. Pestizidak, izurriteen zikloak aldatu, akabatu edo kontrolatzeko substantzia (edo substantzianahasketa) organiko edo inorganikoak dira [18]. Jatorri natural zein sintetikoa izan dezaketen substantzia hauen erabilera zeharo emendatu zen Bigarren Mundu Gerraz geroztik [19], elikadura espezieen produkzio eta hazkuntza hobetuaren bitartez nekazaritza-ekoizpena bikoiztea ahalbidetu zen. Bestetik, metal astunak pisu atomiko eta dentsitate altudun $\left(5 \mathrm{~g} \cdot \mathrm{cm}^{-3}\right.$ gutxienez) elementu inorganiko naturalak dira [20]. Haien artean animalia eta landareentzat funtsezkoak diren elementuak aurkitu daitezke: kobaltoa $(\mathrm{Co})$, kobrea $(\mathrm{Cu})$, kromoa (Cr), manganesoa ( $\mathrm{Mn}$ ) eta zinka ( $\mathrm{Zn})$; edo, funtsezkoak ez diren elementuak: kadmioa $(\mathrm{Cd})$, beruna $(\mathrm{Pb})$ eta merkurioa $(\mathrm{Hg})$.

Konposatu hauek, isurtzen direnean, medioan bertan edo medio ezberdinen artean migra dezakete; izan ere, biosferaren euskarri diren atmosfera, hidrosfera eta litosfera ez dira erlaziorik gabeko konpartimentu estankoak, baizik zuzenki erlazionatuta dauden fluxu konstanteko konpartimentuak 
(horrela Ekosfera sortuz) (1. irudia). Hori dela eta, kutsadurak, aldaketa klimatikoarekin batera, lurzoru emankortasuna kaltetu dezake solido/likido/ gas oreka aldatuz (tenperaturen igoera batek, ebaporazio tasak emendaraziko lituzke, lurzoruetako ur/gas proportzioa eraldatuz, lurzoruak konpaktatuz...) eta lurzoruko karbono organikoaren kantitatea jaitsiz (tenperaturen aldaketa batek deskonposizio/produkzio tasak eraldatuko lituzke). Aldi berean, medio ezberdinetan gertatzen diren aldaketek haietan bizi diren espezieak kaltetu ditzakete; horrela, Zerbitzu Ekosistemikoak kaltetzen dituzte.

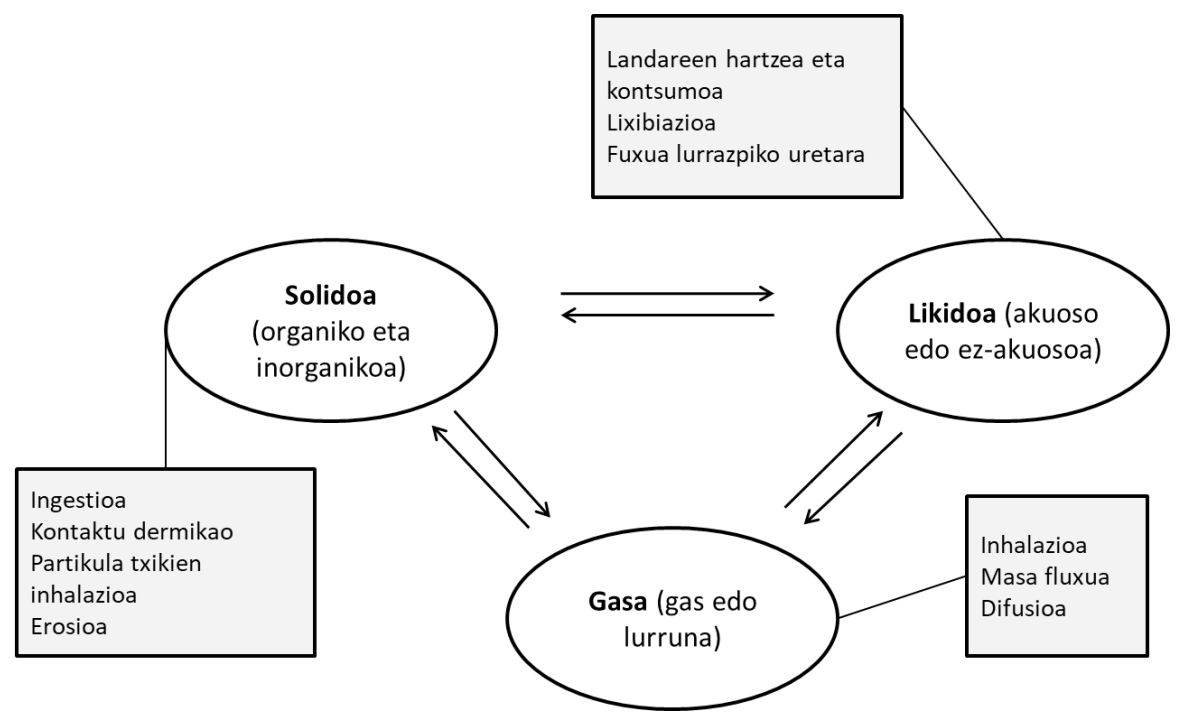

1. irudia. Medio ezberdinen arteko fluxua eta medio bakoitzean bertako organismoenganako kutsatzaileek daukaten esposizio bidea. Scullion 2006-tik [21] hartua eta eraldatua.

\section{ZERBITZU EKOSISTEMIKOAK ETA LURZORUAREN OSASUNA}

Zerbitzu ekosistemikoak giza ongizatean onura duten ondasun ekosistemikoak dira $[13,22,23]$, gizakia hornitzen duten maila ezberdineko ondare eta zerbitzuak barneratzen dituztenak [24-26]. Horrela, 2005. urtean, Millennium Ecosystem Assessment-ek lau kategoria ezberdinetan sailkatu zituen zerbitzu ekosistemikoak: (1) hornitze-zerbitzuak (elikagai, ur, egur, zuntz eta erregaien hornitze zuzen edo ez-zuzena), (2) erregulazio-zerbitzuak (ur eta gas, klima, uholde, erosio edota gaixotasunen erregulazioa), (3) zerbitzu kulturalak (estetikoa, espirituala, hezkuntzazkoa eta aisialdikoa), eta (4) sostengu-zerbitzuak (habitaten sostengua, nutrienteen zikloa, produkzioa eta biodibertsitatea $[23,26]$. 
Ekosistema lurtarren zerbitzuak lurzoru propietateen eta haien elkarrekintzen araberakoak dira; jatorri naturala edo antropikoa izan dezaketen prozesu fisiko-kimiko eta biologikoek baldintzatuak dira batik bat. Erosioek, luiziek, karbono- eta biodibertsitate-beherakadek, edo elementu kutsatzaileek, lurzoruaren degradazioa bultzatzen dute; gaur egun, elikadurasegurtasunean zein sostengarritasun-arloetan aurre egin beharreko erronka izateraino [26-29].

Lurzoruan bizi diren organismoek, ekosistemaren funtsezko zerbitzuetan laguntzeaz gain, sistemaren funtzionamendu jasangarria ahalbidetzen dute. Besteak beste, laguntzen dute nutrienteen zikloa bultzatzen, ura purifikatzen, materia organikoko dinamikak eta egiturak erregulatzen, karbonoa lurrean bahitzen eta berotegi-gasak mantentzen [30]. Zerbitzu horiek, nekazaritza jasangarrirako eta azpiegitura urbanorako baliabide garrantzitsuak izateaz aparte, ezinbestekoak dira ekosistema naturalen funtzionamendurako [31]. Horregatik, lurzoruko populazioetan gerta daitezkeen aldaketek sistema osoaren oreka asalda dezakete; eta garatutako zerbitzu ekonomikoak/ekosistemikoak eragin.

Ekosistema baten kalitatea helburu jakin baten garapenean erakusten duen erabilgarritasun edo efizientziaren bitartez interpretatzen da. Osasunaren kontzeptua, aldiz, funtzionaltasuna barneratzen duen kontzeptu zabalagoa da; hots, funtzioak modu jasangarriagoan garatzea jasotzen duena. Kalitatearen kontzeptuak problema bati kausa-efektu logika linealetik aurre egiten dio; osasunaren kontzeptuak, berriz, EcoHealth eta One Health izenez ezagutzen denak, ente bizi, konplexu eta interrelazionatutzat ulertzen du ekosistema; bizitzaren garapenerako, bai giza bai animalia-bizitzarako, beharrezko dena. Biak, bai Ecohealth bai One Health kontzeptuak, izakera holistikodun fokatze sistemikoak dira, giza osasunaren, animalia-osasunaren eta ingurumen osasunaren arteko elkarrekintza konplexuan oinarritzen direnak [32].

Hamarkadetan zehar, lurzoru baten egoera bere kalitatearen bitartez aztertu izan da; horretarako, kalitate- edo onarpen-atalaseak karakterizazio kimiko eta fisiko-kimikoekin erkatzen dira. Hala ere, azken urteotan agertutako kontzeptu holistikoek erabat aldatu dute fokatze hori. Modu horretan, lurzoruaren osasuna ezagutzeko parametro fisiko eta kimikoez gain lurzoruan bizi diren espezie adierazgarrietan kutsadura efektuak kontuan izatea lortu da arriskua ebaluatzeko orduan.

\section{INGURUMEN-ARRISKUAREN EBALUAZIOA}

Arriskua da akzio edo kondizio zehatz batek sor dezakeen/ditzakeen ondorio kaltegarria/ak gertatzeko probabilitatea, arriskuen konbinazioa eta esposizio ebaluazioa barnean hartuz [33]. Ingurumen-arriskuaren ebalua- 
zioa (ERA, Evaluation Risk Assessment ingelesez) agente arriskutsuek giza osasunean eta kalitate ekologikoan sor ditzaketen elkarrekintzen/inpaktuen ikerketan oinarritzen da; horietan, arriskua identifikatzea, arazoa formulatzea, arriskua analizatzea eta karakterizatzea bilatzen da [33]. Ebaluazio horiek arriskua kudeatzea eta euste- zein erremediazio-neurriak planteatzea ahalbidetzen dute. Izan ere, fokatze hori, lotuta daramatzan kudeaketa modeloekin batera, gero eta erabiliagoa da politika- eta erregulazio-maila ezberdinetan. Giza edo ingurumen-osasunarentzat «onargarriak» diren arrisku-mailak dituzten erregulazioak diseinatzea ahalbidetzen du, eta kokaleku erasokor/sentikorrak alterazio posibleen aurrean lehenesten laguntzen du.

Ingurumen-agentzia, nazioarteko erakundeek eta komunitate zientifikoak zeharo onartu izan dute ezin daitezkeela ingurumen-arrisku ebaluazioak karakterizazio kimiko batean bakarrik oinarritu. Izan ere, ikuspuntu horrek ez du kutsatzaileek biotarengan eragiten dituzten efektuen gaineko informaziorik eskaintzen. Horren harira?, kutsatzaileek eragindako efektu toxikologikoen neurketek omen handia irabazi dute ingurumenaren osasuna ebaluatzeko orduan [34-36]. Horretarako, kutsatzaileek maila ezberdinetan eragin ditzaketen efektuak ebaluatzeko, neurketak egiten dira konplexutasun biologikoko maila desberdinetan. Lurzoruan bizi diren organismoen gaineko arrisku-ebaluazioa 91/414/EEC Kontseilu Direktibak garatutako «SANCO /10329/2002 346 Terrestrial Ecotoxicology Guidance Document»-aren gidaritzapean egiten zen [37]. Direktiba hori, 2011n indargabetuta gelditu zen 1107/2009 (CE) (produktu fitosanitarioen komertzializazioari dagokiona) araudiaren bitartez. Era berean, Batzordearen (EB) 348 283/2013 (REACH: Registration, Evaluation, Authorisation and Restriction of Chemicals ingelesez) eta 284/2013 araudiek baldintza berriak eta osagarriak ezarri zituzten substantzia aktiboen eta landare-osasunerako produktuen (PPP, Plant protection products ingelesez) gainean.

Lurzoru-organismoen gaineko arrisku-ebaluazioak, arrisku-ebaluazio orokorren printzipio berberari jarraitzen diot; hots, (1) arrisku potentzialaren identifikazioa, (2) arrisku potentzialaren karakterizazioa, (3) esposizio-ebaluazioa eta (4) arriskuaren karakterizazioa burutzen ditu. ERA burutzeko, substantzia toxiko ezberdinen inguruko in silico modeloak garatu izan dira. Haien artean, zori modeloak eta efektu modeloak aurkitu daitezke; baita biak konbinatzen dituzten FTE (Fate Transport Effect, ingelesez) modeloak ere [38]. Zori modeloek, ingurumeneko konpartimentu jakin batean aurkitu daitezkeen kontzentrazio kimikoak iragartzen dituzte; hala nola, lurzoru edo erreka batean aurkitu genitzakeen konposatu kimikoen kontzentrazioak. Efektu modeloek, aldiz, gorputz edo konpartimentu biologiko jakin bateko kontzentrazioa efektuetara itzultzen dute. Horretarako, estimatutako kontzentrazioen inpaktua, konplexutasun biologikoko maila ezberdinetara estrapolatzen dute; hots, organismoaren hazkuntzatik, populazio edo komunitatearen garapenetik, ekosistema eta paisaia-aldaketeta- 
tik ekosfera osoa ikertu arte [38]. Hala ere, efektu-modelizazio honetarako, ezinbestekoa da zorizko aurreikuspen egoki bat [39].

\subsection{In silico modeloen erabilera lurzoruen arriskuaren ebaluazioan}

Ingurumen-modelo kuantitatiboen erabilera oso hedatuta dago ERA-n eta ondorengo ingurumeneko erabaki-hartze sistemetan (EDSS: Environmental Decision Support Systems, ingelesez) [40, 41]. Zorizko modeloen artean Elikagaien Babeserako Autoritate Europarrak (EFSA: European Food Safety Authority ingelesez) garatutako PERSAM (Persistence in Soil Analytical Model ingelesez) softwarea aurkitu daiteke. Software hori, lurzoruan zein lurzoruko ur-fasean aurkitu daitezkeen produktuen eta haien azpiproduktuen kontzentrazio-aurreikuspenak (PEC: Predicted Environmental Concentrations, ingelesez) kalkulatzeko garatuta dago. Kalkulurako, egitura espaziala daukaten 62 datu-multzo erabiltzen ditu softwareak: 6 datu-multzo orokor, 27 datu-multzo meteorologiko, lurzoru gainazaleko 5 datu-multzo eta 24 uzta datu-multzo erabiliz.

\begin{tabular}{|c} 
EFSA Data Mask, EFSA European Union \\
Cover, EFSA Regulatory Zones, EFSA \\
Corine Land Cover Data, EFSA \\
Generalized Land Use Map, FOCUS \\
Zones
\end{tabular}

2. irudia. PERSAM softwareak PPPen kalkulurako erabiltzen dituen 64 datu multzoak eta kalkuluetarako gainjarritako mapa datuen 3 adibide: urteko prezipitazio totala (A), urteko batez besteko tenperatura (B) eta gainazaleko materia organikoaren kantitatea $(\mathrm{C})$. 
Modeloak, $1 \times 1 \mathrm{~km}^{2}$-ko bereizmenarekin burutzen ditu kalkuluak, eta esparru horretako lur-erabilera nagusian oinarritzen da. Batik bat pestiziden patua aurreikusteko erabiltzen den software hau gai da, produktuaren/ pestizidaren ezaugarriak sartuta (kom zein koc adsortzio-koefizienteak, pisu molekularra eta DegT50-Degradazio ratioa-) eta aplikazioaren maiztasunak sartuta (urteko aplikazio kantitatea, lehenagoko aplikaziotik pasatako egunak eta fsoil-Lurzorura heltzen den frakzioa-): (a) TIER-1 Aurreikusitako ingurumen-kontzentrazioak (PEC) edo (b) TIER-2 Aurreikusitako ingurumen-kontzentrazioen 95 pertzentila, lurzoru osoan eta lurzoruko fase likidoan, denbora $(0,7,14,21,28$ eta 56 egunetara) eta sakonera desberdinetara $(1,2.5,5$ eta $20 \mathrm{~cm}$-ra) kalkulatzeko. Behin datu horiek izanda, esposizio-aurreikuspen egoki bat izanda, posible litzateke efektu potentzialen azterketa edo modelizazio zehatz bat egitea.

Bestalde, badira giza osasunaren gaineko arriskua kalkula dezaketen efektu-modeloak (HHRA: Human Health Risk Assessment, ingelesez). Horiek substantzia jakin batek errezeptore potentzial batzuen gainean genera dezaketen efektu kaltegarrien karakterizazioa eta kuantifikazioa burutzen dute [41]. Arriskuen ebaluazio honek kontuan hartzen ditu esposizio kimikoen natura, magnitudea, denbora, garraio-mekanismoa, esposizio-bidea eta errezeptoreen sentikortasuna. Modelo hauen artean, Eusko Jaurlaritzak EAE-ko lurzoru kutsatuek gizakiengan sor dezaketen inpaktua ebaluatzeko RBCA (Risk-Based Corrective Action ingelesez) modeloa bermatua aurkitu daiteke. RBCA kimikoen askapenerako lanabes kit-a (RBCA Tool Kit for chemical releases ingelesez) Materialen Testerako Elkarte? Amerikarrak (ASTM: American Society for Testing Materials inglesez) Estatu Batuetan argitaratutako modeloa da [41, 42]. Honek esposizio bide bakoitzerako arrisku-balio indibidualizatua zein metatua kalkulatzea ahalbidetzen du; ezarritako baldintza bakoitzean aurreikusitako atalase balioekiko konparazioa ahalbidetuz. Era horretan, posible da eszenario bakoitzean lorturiko arrisku-balioak atalaseekin konparatzea; hortaz, arriskua edo arrisku-gabezia aurreikus daiteke. Autore batzuek RBCA modeloa arriskuen azterketarako gida estandarizatu eraginkor eta erabilientzat jotzen dute [43]. Izan ere, eredu hau munduan zeharreko hainbat puntu geografikotan aplikatua izan da autoritate erregulatzaile ugariren eskutik [41]. Hala ere, eta erabakiak hartzeko sarri erabili izan den arren (lurzoru kutsatu baten deklarazioan, garbiketa/deskontaminazio-ekintzetan, zigilatzeetan, traza-mailan kutsatutako lurzoruen ikerketetan), emaitza kontserbadoreegiak eta gain-estimatuak sor ditzake RBCA modeloak [43].

Horrela, ERAren sendotasuna eta fidagarritasuna bermatzeko, beharrezkoa da in silico frogekin batera eszenarioak esplizituki frogatzea. Horretarako, ikertu beharreko lekuetan bizi diren espezie esangarriekin burututako toxikotasun-bioentseguak erabil daitezke. 


\section{TEST EKOTOXIKOLOGIKOAK LURZORUKO ESPEZIEEKIN}

Toxikotasun-testetan, organismoak kutsatzaile-kontzentrazio eta mota ezberdinen pean izaten dira medio ezberdinetan (uretan, sedimentuetan edo lurrean), ondoren organismoen hazkuntza, jarrera, eta biziraupena bezalako ezaugarriak ebaluatzeko [44]. Horrela, test hauen bitartez, medio jakin batean dauden kutsadura-mailak organismoengan kalteak sortzeko adinakoak diren (edo ez) ebalua daiteke. OECD, ISO edo EPA bezalako erakundeek nazioartean balioztatutako protokoloak garatu izan dituzte kimiko ezberdinen toxikotasunaren estimaziorako [45]. Ekotoxikotasun-test estandarizatu hauek ahalbidetzen dute eskualde ezberdinetako laborategietan emaitza berdintsuak lortzea, konparazioak erraztea eta ezarritako toxikotasun-neurketen fidagarritasuna areagotzea [46].

Toxikotasun-testen barruan, espezie, medio eta efektu desberdinak ikertzen dituzten entseguak daude. Test estandarren garapenerako espezie modeloak berauen garrantzi ekologikoagatik, laborategi mantenu errazagatik eta belaunaldi denbora laburragatik aukeratuak izan behar dira [47, 48]. Espezie-modelo horien artean, hauek aurkitu daitezke: zizareak (Eisenia andrei eta E. fetida), enkitreidoak (Enchytraeus albidus eta E. crypticus), moluskoak (Helix aspersa), akaroak (Hypoaspis aculeifer, Platynothrus peltifer, eta Oppia nitens), isopodoak (Porcellio scaber eta Porcellionides pruinosis), kolenboloak (Folsomia candida eta $F$. fimetaria), Carabidae familiako intsektuak (Pterostichus oblongpunctatus, Poecilus cupreus eta Oxythyrea funesta) edo bestelakoak [49]. Lurzoru ornogabeez aparte, espezie begetalak erabiltzen dituzten test estandarizatuak ere garatu izan dira kutsatzaile ezberdinen toxikotasuna aztertzeko. Test mota horietan, hazi eta landareetan egin daitezkeen neurketak erabiltzen dira toxikotasuna barematzeko; aipagarrienen artean, Lactuca sativa edo Cucumis sativa espeziekin burutu daitezkeen EPA-ren OPPTS 850.4225 [50] eta OECD-ren 208 [51] (2003) gidalerroak aurkituz. Aipatutako espezieen desberdintasun fisiologiko eta morfologikoei esker (elikatze- eta portaera-ohiturekin batera), kutsatzaileak hartzeko bide desberdinak azter daitezke; lurzoruaren, lurzoru poro-uraren edo airearen esposiziaren bitartez, zein elikaduraren bitartez (lurra jatean) kutsatzaileak inkorporatzen baitituzte [52]. Efektuei dagokienez, toxikotasun testek, parametro letal eta/edo subletalak neur ditzakete [44].

Zizareak [46, 53-56], kolenboloak [57, 58], akaroak [59] eta enkitreidoak [60-62] dira lurzoru ekotoxikologi test-baterietan gehien erabiltzen direnak. Izan ere, hirurogeigarren hamarkadaren bukaeran burutu ziren lurzoruetako lehen toxikotasun-testak [63, 64]; kolenbolo eta zizareak erabiltzen zituzten pestiziden toxikotasuna ebaluatzeko [65, 66]. Zizareak, kutsaduraren aurrean modu sentikor eta neurgarrian erantzuten duten metal-metatzaile efizienteak dira. Ondorioz, organismo behale hauen era- 
bilpena zeharo zabaldu da lurzoruen kutsadura ikerketetan; bereiziki, E. fetida/E. andrei espeziak izanik erabilienak.

E. fetida (Savigny, 1826) lurrean deskonposatzen ari den materia organikoan, konpostean eta lizunean bizi den zizare epigeikoa da [67]. Organismo hauek, ezinbesteko zeregina burutzen dute lurzoru formazioan, MOaren deskonposaketan eta nutrienteen berziklapenean [68]. Ugalketa-ziklo erlatiboki laburra dauka [69], arrautzen eklosiotik 21-30 egunetan (baldintza optimoetan) heldutasuna lortuz eta 45-51 egunetan hurrengo belaunaldia sortuz [70]. Arrautzen lurreratzea, kopularen ondorengo 48 orduetan gertatzen da, oinordekotzaren produkzioa 0.35 eta 1.3 arrautza/egun-etakoa izanik. Hala ere, eta zizareek urte osoan arrautzak produzitu ditzaketen arren, urtaroen arteko hezetasun, tenperatura, janari eta bestelako faktoreen aldaketek, populazioen tamaina eta biomasetan eragin dezakete [71, 72]. Jaiotzen diren oinordekoen kantitateak 2.5 eta 3.8 bitartean oszila dezake; tenperaturaren ondorioz batik-bat [73].

Espezie hau kutsatzaile kimikoek eragindako toxikotasunaren erakusle ona izateaz gain, estres-faktore anitzen efektuak [74], lurzoruaren egoera fisikoa (konpaktazioa/trinkotzea, hidrologia, eta abar) eta lurzoru-erabilpenak ebaluatzeko adierazle sentikor eta egokia da [75]. Honek guztiak, organismo merkea, egokia eta eztabaida etiko bakoa izatearekin batera, esperimentaziorako modelo-organismo oso erabilia izatea bultzatu du [14, 67]. E. fetida zizareak kutsadurarekiko erakutsi izan duten sentikortasuna dela eta, zabalki erabiliak izan dira zenbait organismo internazionalek argitaratutako toxikotasun-test estandarizatuetan [53-56] lurzoruen afekzioak ikertzeko [76-81].

\subsection{Toxikotasun testak Eisenia fetida zizarearekin}

Kutsatzaileek E. fetidan eragin dezaketen arrisku potentzialak ebaluatzeko, toxikotasun-test akutuak eta kronikoak aurkitu daitezke. Test akutuen [55] artean, heriotza dosia $\left(\mathrm{LC}_{50}\right)$ bilatzen duten Paper kontaktuko testa eta Lurzoru artifizaleko testa aurkitu daitezke. Lehenengoan, ikertu nahi den sustantziaz hezetutako paperararekin kontaktuan jartzen dira zizareak bi egunetan zehar; efektu kimikoen behaketa arin bat egiteko eta kimikoen hartze eta biotransformazioen azterketa burutzeko teknika erabilgarria dira [49]. Hala ere, test mota honek esposizio dermiko bidezko toxikotasuna antzematen du batik bat [82]; ingestio bidezko toxikoen barneratzea (fase solidoan egongo liratekeenak) ebaluatzeko, lurzoru bidezko esposizioaren beharra dago [80, 83, 84]. Lurzoru artifizialeko testek, kimikoek zizareengan eragiten dituzten toxikotasun-efektuen datu adierazgarriagoak eskaintzen dituzte; horretarako, substratutzat $\% 70$ harez, \% 20 buztinez eta $\% 10$ turbaz eginiko lurzoru artifizialak erabiltzen dira [55]. Azken urteotan, baldintza errealen adierazgarritasuna hobetzeko xedez, LUFA lurzoru 
natural eta estandarren erabilera hedatzen hasi da [85]. Izan ere, Alemanian (Speyer) komertzializatutako lurzoruen MO kantitatea (\% 1.25-5.36 bitartean) OECD lurzoruena baino baxuagoa da; nekazaritza-lurzoruetara gehiago hurbilduz $(\%<10)$ [49].

Behin kutsatzaileak organismo barnean daudela, kalte fisiologiko ezberdinak eragin ditzakete; hazkuntzan, elikagaien asimilazioan zein ugalketarako energia-gastuan, azkenik norbanakoen heriotza eragin arte [80]. Hala ere, lurzoruko organismoenganako efektu toxikologikoak ikertzeko froga hedatuak diren arren, efektu subletal asko: portaera-aldaketak, ugalketa-aldaketak, inhibizio entzimatikoa edo kalte genetikoa bezalakoak, ez dira erasotzen toxikotasun akuturako test hauetan.

Populazioen dinamikan daukan garrantzia dela eta, azpimarratzekoa da ugalketa-azterketek toxikologian duten garrantzia [86, 87]. OECD-222 testa, adibidez, agente kimiko ezberdinek ugalketa errendimenduan sor zitzaketen efektuak aztertzeko diseinatutako testa da. Espresuki, hilkortasuneta hazkuntza-parametroak neurtzen dira 4 astean zehar (28 egun) esposiziopean izandako zizareetan; 56 egunetara ugalketaren gaineko efektuak (oinordekotza) ebaluatzen diren heinean. Modu honetan, eta entsegu hau erreprodukzio-parametroak lortzeko diseinatuta dagoen arren, indikatzaile askoren lorpenerako (ECx, LCx, LOEC edo NOEC) test baliagarria da.

Aipatutako toxikotasun testetatik eratorritako heriotza- eta ugalketa-parametroak agente kimikoen arrisku ebaluazio eta erregulaziorako garrantzi handikoak dira [87-89]. Hala ere, azken hamarkadetan, ikerkuntzaren esfortzuak azterketa hauen sakontzean jardun dira, ekotoxikologia modernoaren esparruan biomarkatzaile berriak garatuz eta balidatuz [80].

\subsection{Biomarkatzaileen neurketa $\boldsymbol{E}$. fetida zizarean}

Biomarkatzaileak, kutsatzaileenganako esposiziorik eta/edo efekturik izan den ala ez argituko duten parametro neurgarriak dira. Konplexutasun biologiko sinpleenetan (maila molekularrean, zelularrean, ehun-mailan) neurtzen diren arren, maila biologiko konplexuagoetan gerta daitezkeen (populazio-, komunitate- edo ekosistema-mailan) aldaketak aurreikusteko duten ahalmenagatik [90], diagnosi goiztiarrak burutzeko tresna eraginkor bezala erabiliak dira. Neurketa kimikoek ez bezala, biomarkatzaileek, kutsatzaileek eragindako inpaktu biologikoen garrantziari buruzko informazioa eskaintzen dute [36, 91]. Horregatik, kutsatzeileek lurzoru-ekosistemetan eragin ditzaketen efektuak kuantifikatzeko, lurzoru ornogabeetan (E. fetida kasu) aplikaturiko biomarkatzaileen gaineko interesa asko hazi da azken urteotan [80, 92-94]. E. fetida zizareetan gehien erabiltzen diren biomarkatzaileen artean, DNA alterazioen behatzeak (maila molekularra), metalei elkartzen zaizkien proteina (MT-Methallothioneins - eta MBP-Metal binding proteins- ingelesez), kolinesterasa eta erantzun entzimatikoen 
neurketak, energia gordekinen kuantifikazioa (maila biokimikoa), lisosomen mintz egonkortasunaren azterketa (maila zelularra), espermaren kalitatea eta erantzun immunologiko, neurologiko, histologiko (ehun-maila) eta portaerazkoen analisiak aurkitu daitezke [78, 94-97]. Frogatua izan da, gainera, metalekin kutsatutako lurzoruek mintz lisosomikoaren ezegonkortasuna [93, 98], aktibitate entzimatikoa eta geneen adierazpena [99-101], estres oxidatiboa $[88,102,103]$ zein DNA-an kalteak [104-105] eragin ditzaketela.

Azken hamarkadan, maila zelularreko biomarkatzaileen garapenean emendio argia gertatu da; haien artean, zizareen zelula immunitarioetan (zelomozitoetan) aplikaturikoak nabarmentzen dira. Zelomozitoak barrunbe zelomikoko likido zelomikoan aske dauden zelula immunitarioak dira; gizakien leukozitoen homologoak [107]. Likido zelomiko hau, esekiduran daramatzan zelomozitoekin batera, zizareen lakainetako nefridio pareetatik eta poro dortsaletatik kanporatzen da [67, 108], eta ezinbesteko rola du material ezezagunen errekonozimenduan eta eliminazioan zein zaurien koagulazio eta orbaitzean $[109,110]$. Funtzio horietarako, entzima hemolitiko, proteolitiko eta zitotoxikoez baliatzen dira zelomozitoak [110]. Zelomozitoen artean, pigmentazio, ultraegitura, funtzio, konposizio granular zein portaera desberdina (atxikidura eta kimiostasi) duten [111] bi subpopulazio nagusi bereiz daitezke: amebozitoak eta eleozitoak [112-114].

Amebozitoak (pikortsu edo hialinoak), zelomozito mota ugarienak dira [115]. Zelomaren estalki mesenkimatikoan jatorri duten zelula hauek [111] aktibitate fagozitiko eta enkapsulatzaile handia duten immunozito eragileak dira $[107,114]$. Eleozitoak, aldiz, liseri-traktua estaltzen duten zelula kloragogenikoetatik askatzean sortzen diren zelulak dira [116]. Osatzen dituzten bikor (kloragosomak) ezberdinek [108, 116, 117] eta erriboflabina-metaketa selektiboek eragindako autofloreszentziak [108, 118] oso bereizgarriak bilakatzen ditu. Zelomozito hauek ornogabeen zelula hepatikoen funtzio berdintsuak dituzte [108], eta nutrizio-funtzioa daukaten glikogeno eta lipidoen metabolismo, biltegiratze $[67,108]$ eta garraioan $[111,116]$ jarduten dira. Gainera, aktibitate fagozitikorik ez duten arren, zizareen homeostasi eta immunitate humoralean parte hartzen dute $[80,108,114,115]$; horretarako, peptido antimikrobianoak bezalako faktore humoralak ekoizten dituzte $[67,108]$.

Zizareetan neurtzen diren maila zelularreko biomarkatzaileak, zelomozitoen lisosoma mintzaren egonkortasunean zentratu izan dira batik bat. Lisosomen bakuola sistema, endozitosiz barneratutako kutsatzaileen (metalak edo elementu organikoak) edo zeluletako hondakinen metatzean eta kanporatzean oinarritzen da $[119,120]$. Hori dela eta, lisosomen patologia-azterketa (mintz egonkortasunaren azterketa barne) oso erabilia izan da ingurumen-inpaktuak aztertzeko orduan. Spurgeon-ek [121] (2005) lisosoma-mintzaren egonkortasun-neurketa (biomarkatzaile molekular eta 
biokimikoekin batera) metalek sortutako estresa neurtzeko biomarkatzaile sentikorrenen artean sartu zuen. Horrek bultzatuta, ugariak izan dira azken hamarkadetan zelomozitoekin garatutako testak; mikroplaketarako garatutako MTT, XTT (zelulen aktibitate metabolikoa neurtzen dute), NRU (Neutral Red Uptake) edo Kaltzeina-AM zelula bideragarritasun-testak, kasurako. Kaltzein AM testa, esterasen aktibitatean oinarritzen den [122] bideragarritasun zelularra eta zitotoxikotasuna neurtzeko metodo arin, sinple eta zehatza da [80]. Kaltzeina zetometil esterra (Calcein AM) zelula barnera sartzen da; behin barnean, esterasa intrazelularrek zitoplasman metatu den kaltzeina hidrolizatzen dute, zeina konposatu hidrofiliko fluoreszentea bilakatzen den. Fluoreszentzia horren beherakadak, mintz zelularraren kaltea iragarriko luke; organismoa estres kimiko (metal astunek eragindakoa kasu) edo fisikopean dagoela iradokiz. Berriki, zelomozitoen bideragarritasunaz gain, zelomozito kontzentrazioa ere erabili izan da metalen inpaktua ebaluatzeko biomarkatzaile gisa [123].

\section{LURZORU KUTSATUEN DIAGNOSIA: IKUSPUNTU HOLISTIKOA}

Aktibitate antropikoa dela eta kutsatua izan den lurzoru baten karakterizazioa burutzeko, ezinbestekoa da afekzio kimiko eta biologikoak behar bezala aztertzea; batez ere, kutsatzaileek izaki bizidunengan eta ekosistemetan sor dezaketen arriskua barematzeko.

In silico modeloak kutsatzaile baten isuri/aplikazio baten osteko ingurumen kontzentrazioak aurreikusteko tresna egokiak dira; gainera, oso lagungarriak entsegu ekotoxikologikoetako dosien ezarpenean. Aldiz, kutsatutako lurzoru bat kudeatzeko, eta efektu biologikoak aurreikusteko, ezinbestekoa da kutsatutako lurzoruaren toxikotasuna aztertzea; zeregin horretan, ezinbestekoak dira toxikotasun-testak eta biomarkatzaile biologikoak. Haien bitartez, konposatu jakin batzuek baldintza zehatzen pean organismoengan eragiten dituzten efektu biologikoak ikertzea bilatzen da; era horretan, $\mathrm{LC}_{50}$, NOEC, LOEC edo $\mathrm{EC}_{50}$ bezalako hilgarritasun- edo efektuparametroak eskuratzen dira Era berean, parametro horiek efektu modeloak eta FTE modeloak elikatzeko erabil daitezke; horrela, lurzoruarekiko esposizio jakin batek edo lurzoru-erabilera jakin batek ekarriko lukeen arriskuaren kuantifikazioa egiten lagunduko lukete.

Esan bezala, efektu modeloak eta FTE modeloak ikertutako toxikotasun atalase biologikoetan oinarritzen dira arriskuaren kuantifikazioa burutzeko. Hala ere, test ekotoxikologiko hauek, laborategi baldintzetan eta kutsagai bakarren pean burutakoak izaten dira gehienetan; antzekotasun gutxi zelai baldintzekin. Laborategi-baldintza optimoetan kalkulatutako atalaseak efektu modeloetan erabiltzeko, estimazioak ziurgabetasun-koefizien- 
teekin doitzen dira; gehienetan, arreta-printzipioa kontuan hartzen da. Horrela, efektu modeloek aurreikusitako eszenarioak zehaztasun gabekoak eta ziurgabetasun altukoak izaten dira gehienetan; sarri, inpaktuak gehiegi balioetsiz.

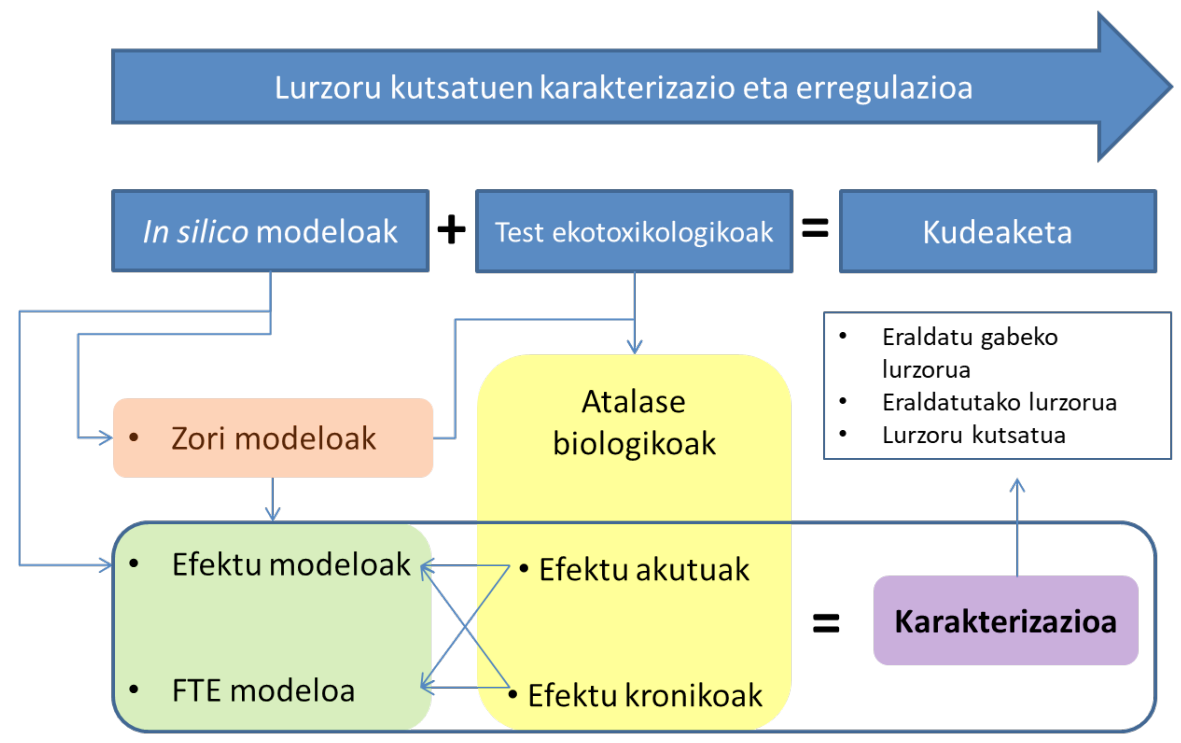

3. irudia. Lurzoru kutsatuen karakterizazio eta erregulaziorako erreminten arteko erlazioak.

Hau esanda, eta efektu-modeloak behar bezala elikatzeko, ezinbestekoa da ebaluatu beharreko lurzoruekin test ekotoxikologiko zehatzak burutzea. Horrela, estimatutako arriskua zehatzagoa izango da; eta horrela, baita ondorengo kudeaketa ere.

Behin lurzoru kutsatuen arriskua zehaztuta, lursailen itxiera, erabileraren aldaketa edo arriskua arintzea jorratuko dira; horretarako, betiere, lan ekotoxikologikoetan eta arrisku ebaluazioetan oinarrituko gara. Arriskuaren murrizketa, in silico eta ekotoxikologia lanen bitartez monitorizatutako biorremediazio-prozesuen bitartez, adibidez.

\section{ESKER ONAK}

Egileen esker onak MINECOko CTM2017-87766-R proiektuari, Biorem proiektuari (IHOBE, Ekoberrikuntza 2017 deialdia) eta Gernikako Udalari, elkarrekin xedatutako hitzarmenak (2018/12/11) lan hau posible egin duelako. 


\section{BIBLIOGRAFIA}

[1] United Nations, World Population Prospects, 2019: HighlightsGarcia, S. N., Osburn, B.I., Cullor, J.S., 2019. A one health perspective on dairy production and dairy food safety. One Hea. 7, 100086.Eurostat, 2020.

[2] World Meteorogical Organization (WMO). Greenhouse gas concentrations in atmosphere reach yet another high. 25 November 2019. Press Release Number: 25112019. https://public.wmo.int/en/media/press-release/greenhouse-gas-concentrations-atmosphere-reach-yet-another-high.

[3] Sherwood, S., Bony, S., Dufresne, J. 2014. Spread in model climate sensitivity traced to atmospheric convective mixing. Nature 505, 37-42.

[4] Comunicación de la Comisión al Parlamento Europeo, al Consejo, al Comité Económico y Social Europeo y al Comité de las Regiones. 2018 COM .

[5] Smith P., Fang C., Dawson J.J.C., Moncrieff J.B. 2008. Impact of Global Warming on Soil Organic Carbon. Adv. in Agron. 97, 1-43.

[6] Andrady, A.L. 2011. Mar. Pollu. Bull. 62. 1.596-1.605.

[7] Rochman, C.M.; Manzano, C.; Hentschel, B.T.; Simonich, S.L.M. 2013. Env. Sci. and Tech.,. 47,. 1.3976-1.384.

[8] Ivar do Sul, J.A.; Costa, M.F. 2014, Environ. Poll. 185,. 352-364.

[9] Pereira, P., Bogunovic, I., Munoz-Rojas, M., Brevik, E.C. 2018. Soil ecosystem services, sustainability, valuation and management., Curr Opi in Environ Sci \& Health. 5, 7-13.

[10] Yang L., Zhang Y., Kang S., Wang Z., Wu C. 2021. 2021.Microplastics in soil: A review on methods, occurrence, sources, and potential risk. Sci. of The Tot. Env. 780,146546

[11] Van den Berg, P., Huerta-Lwanga, E., Corradini, F., Geissen, V., 2020. Sewage sludge application as a vehicle for microplastics in eastern Spanish agricultural soils. Environ. Pollut. 261, 114198.

[12] Guo, J., Huang, X.-P., Xiang, L.,Wang, Y.-Z., Li, Y.-W., Li, H., Cai, Q.-Y., Mo, C.-H.,Wong, M.-H., 2020. Source, migration and toxicology of microplastics in soil. Environ. Int. 137,105263

[13] FAO. 2015. Status of the World's Soil Resources (main Report) European Environmental Agency (2014) Progress in Management of Contaminated Sites.

[14] Shi, Z., Tang, Z., Wang, C. A. 2017. A brief review and evaluation of earthworm biomarkers in soil pollution assessment. Environ. Sci. Pollut. Res. Int. May; 24(15): 13284-13294.

[15] European Environment Agency (EEA). 2014. LSI 003.Published 02 May 2014. Last modified 17 Jan 2019.

[16] Cachada, A., Rocha-Santos, T., Duarte, A. C. 2018 Chapter 1 - Soil and Pollution: An Introduction to the Main Issues. Editor(s): Armando C. Duarte, Anabela Cachada, Teresa Rocha-Santos.Soil Poll,Acad Press, 1-28.

[17] Castelo-Grande, T., Augusto, P.A., Monteiro, P., Estevez, A.M., Barbosa, D. 2010. Remediation of soils contaminated with pesticides: a review, International Journal of Environ. Analy.1 Chem, 90:3-6, 438-467. 
[18] Santos, F.J., Galceran, M.T. 2002.Trends in Anal. Chemosph. 21, 672.

[19] Liu, P., Yang, Y., Li, M., 2020. Responses of soil and earthworm gut bacterial communities to heavy metal contamination. Environ. Poll.. 265, Part B,114921.

[20] Scullion, J. Remediating polluted soils. Naturwissenschaften. 2006 Feb; 93(2):51-65.

[21] Dominati, E., Patterson, M., Mackay, A. 2010. A framework for classifying and quantifying the natural capital and ecosystem services of soils. Ecol. Econ. 1858-1868.

[22] Jónsson, J.Ö.G., Davíosdóttir, B. 2016. Classification and valuation of soil ecosystem services. Agricu.Sys., 145, 24-38.

[23] Costanza, R., d'Arge, R., de Groot, R., Farber, S., Grasso, M., Hannon, B., Limburg, K., Naeem, S., O’Neill, R.V ., Paruelo, J., Raskin, R.G., Sutton, P., van den Belt, M., 1997. The value of the world's ecosystem services and natural capital. Nature 387 (6630), 253-260.

[24] MEA, 2005.MillenniumEcosystem Assessment: Ecosystems and $\mathrm{Hu}-$ manWell-being 5. Island Press Washington, DC.

[25] Adhikari, K., Hartemink, A.E. 2016. Linking soils to ecosystem services A global review, Geoder. 262, 101-111.

[26] Oldeman, L.R., 1998. Soil Degradation: A Threat to Food Security. International Soil Reference and Information Center, Wageningen.

[27] Godfray, H.C.J., Beddington, J.R., Crute, I.R., Haddad, L., Lawrence, D., Muir, J.F., Pretty, J., Robinson, S., Thomas, S.M., Toulmin, C., 2010. Food security: the challenge of feeding 9 billion people. Science 327 (5967), 812 818.

[28] Montgomery, H.L., 2010. How Is Soil Made? Crabtree Publishing, New York.

[29] Breure, A.M., De Deyn, G.B., Dominati, E., Eglin, T., Hedlund, K., Van Orshoven, J., Posthuma, L. 2012. Ecosystem services: a useful concept for soil policy making! Curr Opin in Environ Sustain. 4. 5. 578-585.

[30] European Food Safety Authority (EFSA). 2010. Panel on Plant Protection Products and their Residues (PPR). Scientific Opinion on the development of specific protection goal options for environmental risk assessment of pesticides, in particular in relation to the revision of the Guidance Documents on Aquatic and Terrestrial Ecotoxicology (SANCO/3268/2001 and SANCO/10329/2002). EFSA Jour., 8(10), 1821.

[31] Harrison, S., Kivuti-Bitok, L., Macmillan, A., Priest, P. 2019.EcoHealth and One Health: A theory-focused review in response to calls for convergence. Environ.Intern. Volume 132, 105058.

[32] Muralikrishna, I.V., Manickam, V. 2017. Chapter Eight - Environmental Risk Assessment, Editor(s): Iyyanki V. Muralikrishna, Valli Manickam. Environ. Manag., Butterworth-Heinemann, 135152.

[33] Bayne, B.L., 1989. Measuring the biological effect of pollution: the mussel watch approach. Wat. Sci. Tech., 21: 1089-1100. 
[34] Gray, J.S., 1992. Biological and ecological effects of marine pollutants and their detection. Mar Poll Bull, 25: 48-50.

[35] Marigómez, I., Soto, M., Orbea, A., Cancio, I., Cajaraville, M. 2004. Chapter 14 Biomonitoring of environmental pollution along the Basque coast, using molecular, cellular and tissue-level biomarkers: an integrative approach. Elsevier Ocean.Series. 70.

[36] SANCO /10329/2002 346 Terrestrial Ecotoxicology Guidance Document».

[37] Jørgensen, S.E., Fath, B.D.. 2011. 8 - Ecotoxicological Models. Editor(s): Sven Erik Jørgensen, Brian D. Fath. Dev. in Environ. Mod. 23, 229-290.

[38] Tiktak, A., Boesten, J.J.T.I., Egsmose, M., Gardi, C., Klein, M., Vanderborght, J. 2013. European scenarios for exposure of soil organisms to pesticides, Journ. of Environ. Sci. and Hea., Part B, 48:9, 703716.

[39] Bennett, N.D., Croke, B.F.W., Guariso, G., Guillaume, J.H.A., Hamilton, S.H., Jakeman, A.J., Marsili-Libelli, S., Newhama, L.T.H., Norton, J.P., Perrin, C., Pierce, S.A., Robson, B., Seppelt, R., Voinov, A.A., Fath, B.D., Andreassian, V., 2013. Characterising performance of environmental models. Environ. Modell. Softw. 40, 1e20.

[40] Pinedo, J., Ibáñez, R., Irabien, Á. 2014. A comparison of models for assessing human risks of petroleum hydrocarbons in polluted soils. Environ. Mod. \& Soft.. 55, 61-69.

[41] Galán E., Aparicio P., Romero A. 2014. El programa RBCA aplicado a suelos contaminados por elementos traza. Ventajas e inconvenientes. XXXIV Reunión de la Sociedad Española de Mineralogía.

[42] Tsai, T.T., Kao, C.M., Surampali, R.Y., Huang, W.Y., Prao, J.P.2001. Sensitivity analysis of risk assessment at a petroleum-hydrocarbon contaminated site. J. Hazard. Toxic. Radioact. Waste, pp. 89-98.

[43] EPA-United States Environmental Protection Agency Office of Solid Waste and Emergency Response Publication. 1994. Inter. Bull.. 2-1. 9345.0-05I

[44] Davies, N.A., Hodson,M.E., Black, S. 2003. Is the OECD acute worm toxicity test environmentally relevant? The effect of mineral form on calculated lead toxicity. Environ Pollut.;121(1):49-54.

[45] Lopes Alves, P.R., Nogueira Cardoso, E.J.B. 2016. Overview of the Standard Methods for Soil Ecotoxicology Testing, Invertebrates - Experimental Models in Toxicity Screening, Marcelo L. Larramendy and Sonia Soloneski, IntechOpen, DOI: 10.5772/62228.

[46] Ronday, R, Houx, N.W.H. 1996. Suitability of seven species of soil-inhabiting invertebrates for testing toxicity of pesticides in soil pore water. Pedobiol.;40:106-112.

[47] Fountain, M.T., Hopkin, S.P. Folsomia candida (Collembola): A «Standard» soil arthropod. Ann Rev Entom. 2005;50:201-22.

[48] Van Gestel, C.A. 2012. Soil ecotoxicology: state of the art and future directions. Zookeys. (176): 275-96.

[49] US EPA, OPPTS 850.4225. 1996. Seedling emergence, Tier II. Ecological effects test guidelines. United States Environmental Protection Agency. 
[50] OECD Guidelines for the Testing of Chemicals No. 208: Terrestrial Plant Test: Seedling Emergence and Seedling Growth Test, Organization for Economic Co-operation and Development;Section 2, OECD Publishing, Paris, 2006.

[51] Peijnenburg, W., Capri, E., Kula, C., Liess, M., Luttik, R., Montforts, M., Nienstedt, K., Rombke, J., Sousa, J.P., Jensen, J. 2012. Evaluation of exposure metrics for effect assessment of soil invertebrates. Crit. Rev. in Environ. Sci. and Tech. 42:1862-1893.

[52] ISO. Soil Quality no 11268-1.2012. Soil quality - Effects of pollutants on earthworms - Part 1: Determination of acute toxicity to Eisenia fetida/Eisenia andrei. Reviewed and confirmed in 2018.

[53] ISO. Soil Quality no 11268-2.2012. Soil quality - Effects of pollutants on earthworms - Part 2: Determination of effects on reproduction of Eisenia fetida/Eisenia andrei. Reviewed and confirmed in 2018.

[54] OECD. Guidelines for the Testing of Chemicals No. 207: Earthworm, Acute Toxicity Tests. Paris: Organization for Economic Co-operation and Development; 1984.

[55] OECD. Guideline for the Testing of Chemicals No.222. Earthworm ReproductionTests-222. Organization for Economic Co-operation and Development; 2016.

[56] ISO. Soil Quality no.11267. 2014. Soil quality - Inhibition of reproduction of Collembola (Folsomia candida) by soil contaminants

[57] OECD. Guidelines for the testing of Chemicals No. 232: Collembolan Reproduction Test in Soil. Organization for Economic Co-operation and Development; 2009.

[58] Van Gestel, C.A.M., Léon, C.D., Van Straalen, N.M. 1997. Evaluation of soil fauna ecotoxicity tests regarding their use in risk assessment. In: Tarradellas J, Bitton G, Rossel D, editors. Soil Ecotoxicol.. Boca Raton: CRC Press; pp. 291-317.

[59] Jänsch S, Amorim MJ, Römbke J. 2005.Identification of the ecological requirements of important terrestrial ecotoxicological test species. Environ. Rev.;13:51-83.ISO.

[60] Soil quality No. 16387: Effects of Pollutants on Enchytraeidae (Enchytraeus sp.) - Determination of Effects on Reproduction and Survival. Geneva: International Standardization Organization; 2004.

[61] OECD. Guidelines for the Testing of Chemicals No. 220: Enchytraeid Reproduction Test. Paris: Organization for Economic Co-operation and Development; 2004

[62] Fox CJS .1964. The effect of five herbicides on the number of certain invertebrate animals in grassland soil. Canadian Jour of Plan Sci 44: 405-409.

[63] Edwards, C.A. 1969. Soil pollutants and soil animals. Sci.Americ. 220: 88-99.

[64] Ghabbour, S.I., Imam, M. 1967. The effect of five herbicides on three Oligochaete species. Rev Ecol Biol 4: 119-122. 
[65] Scopes, N.E.A., Lichtenstein, E.P.1967. The use of Folsomia fimetaria and Drosophila melanogaster as test insects for the detection of insecticide residues. Jour of Econ.Entom 60: 1539-1541.

[66] Bilej, M., Procházková, P., Silerová, M., Josková, R., 2010. Earthworm immunity, in: Söderhäll, K. (Ed.), Invertebrate Immunity. Landes Bioscience and Springer Science+Bussiness Media.

[67] Gaete, H., Hidalgo, M.E., Neaman, A., Ávila, G., 2010. Evaluación de la toxicidad de cobre en suelos a través de biomarcadores de estrés oxidativo en Eisenia foetida, Quim. Nova. 33, 3, 566-570.

[68] Walker, C.H., Hopkin, S.P., Sibly, R.M. \& Peakall, D.B. 1996. Principles of Ecotoxicology. Bristol, PA:Taylor \& Francis, Inc

[69] Dominguez, J. In: Edwards CA, editor. Earthworm Ecology. Boca Raton, Florida: CRC Press; 2004. p. 401-24.

[70] Edwards, CA, Bohlen CJ. 1996. Biology and Ecology of Earthworms. 3rd ed. London: Chapman \& Hall.

[71] EFSA Panel on Plant Protection Products and their Residues (PPR), Ockleford, C., Adriaanse, P. Berny, P. Brock, T. Duquesne, S., Grilli, S., Hernandez Jerez, A., Bennekou, S. Klein, M., Kuhl, T., Laskowski, R., Machera, K., Pelkonen, O., Pieper, S., Stemmer, M., Sundh, I., Teodorović, I., Tiktak, A., Topping, C., Smith, R. 2017. Scientific Opinion addressing the state of the science on risk assessment of plant protection products for in-soil organisms. The EFSA Jour. 15. 4690.

[72] Domínguez, J., Ferreiro, A., Velando, A.. 2005. Are Eisenia fetida (Savigny, 1826) and Eisenia andrei Bouche (1972) (Oligochaeta, Lumbricidae different biological species?.Pedobiologia 49 (2005) $81-87$

[73] Hund-Rinke, K., Wiechering, H. 2001. Earthworm avoidance test for soil assessments: An alternative for acute and reproduction tests. J. Soils Sed. 1, 15-20.

[74] Lee, K.E.; 1985. Earthworms: Their Ecology and Relationships with Soils and Land Use. Acad. Press, Sydney.

[75] Ernst, G., Zimmermann, S., Christie, P., Frey, B., 2008. Mercury, cadmium and lead concentrations in different ecophysiological groups of earthworms in forest soils. Environ. Pollut. 156, 1304-1313.

[76] Asensio, M.V., 2009. Health assessment of polluted soils after Eisenia foetida ex situ bioassays based on conventional and in vitro cellular biomarkers and microarray technology. Ph D Thesis, Departamento de Zoología y Biología Animal. Euskal Herriko Unibertsitatea.

[77] Irizar, A., Duarte, D., Guilhermino, L., Marigómez, I., Soto, M. 2014. Optimization of NRU assay in primary cultures of Eisenia fetida for metal toxicity assessment. Ecotoxicol. 23(7): 1326-35.

[78] Garcia-Velasco, N., Gandariasbeitia, M., Irizar, A., Soto, M. 2016. Uptake route and resulting toxicity of silver nanoparticles in Eisenia fetida earthworm exposed through standard OECD tests. Ecotoxicol. 25, 1543-1555.

[79] Garcia-Velasco, N., Peña-Cearra, A., Bilbao, E., Zaldibar, B., Soto, M. 2017. Integrative assessment of the effects produced by Ag nanoparticles at diffe- 
rent levels of biological complexity in Eisenia fetida maintained in two standard soils (OECD and LUFA 2.3). Chemosph. 181, 747-758.

[80] Urionabarrenetxea, E., Garcia-Velasco, N., Marigómez, I., Soto, M. 2020. Effects of elevated temperatures and cadmium exposure on stress biomarkers at different biological complexity levels in Eisenia fetida earthworms. Comp. Biochem. Phys. Part C: Tox.\& Pharmaco., Vol 231, 108735.

[81] Urionabarrenetxea, E., Garcia-Velasco, N., Anza, M., Artetxe, U., Lacalle, R., Garbisu, C., Becerril, T., Soto, M. Application of in situ bioremediation strategies in soils amended with sewage sludges. Sci. of The Tot. Environ. 766,144099 .

[82] Belfroid, A., Sikkenk, M., Seinen, W., Gestel, K.V., Hermens, J., 1994. The toxicokinetic behavior of chlorobenzenes in earthworms (Eisenia andrei) experiments in soils. Environ. Tox. and Chem. 13, 93-99.

[83] Contreras-Ramos, S.M., Álvarez-Bernal, D., Dendooven, L., 2006. Eisenia fetida increased removal of polycyclic aromatic hydrocarbons from soil. Environ. Pol-lut. 141, 340-396.

[84] Løkke, H., Van Gestel, C.A.M. (Eds) .1998. Handbook of Soil Invertebrate Toxicity Tests. John Wiley \& Sons, Chichester.Joosse, E. N. G., Verhoef, S. G. 1983. Lead tolerance in Collembola. Pedobiol., 25, 1118.

[85] Kooijman, S. A. L. M., Metz, J. A. J. .1984. On the dynamics of chemically stressed populations: the deduction of population consequences from effects on individuals. Ecotoxicol. Environ. SaJ., 8, 25474.

[86] Spurgeon, D., Hopkin, S., Jones, D., 1994. Effects of cadmium, copper, lead and zinc on growth, reproduction and survival of the earthworm Eisenia fetida (Savigny): assessing the environmental impact of point-source metal contamination in terrestrial ecosystems. Environ. Pollut. 84 (2), 123-130.

[87] Spurgeon, D.J., Stürzenbaum, S.R., Svendsen, C., Hankard, P.K., Morgan, A.J., Weeks,J.M., Kille, P., 2004. Toxicological, cellular and gene expression responses in earthworms exposed to copper and cadmium. Comp. Biochem. Physiol. C. 138, 11-21.

[88] Rodriguez-Ruiz, A., Asensio, V. Zaldibar, B., Soto, M., Marigomez, I., 2014. Toxicity assessment though multiple endpoint bioassays in soils posing environmental risk according to regulatory screening values. Environ. Sci. Pollut. Res. 21, 9689-9708.

[89] Spurgeon, D. J., Ricketts, H., Svendsen, C., Morgan, A. J., Kille, P. 2005. Hierarchial responses of soil inver-tebrates (earthworms) to toxic metal stress. Environ Sci Technol. 2005 Jul 15;39(14):5327-34.

[90] Kammenga, J.E., Dallinger, R., Donker, M.H., Köhler, H.R., Simonsen, V., Triebskorn, R., Weeks, J.M. 2000.Biomarkers in terrestrial invertebrates for ecotoxicological soil risk assessment. Rev. of Environ. Contam. and Toxicol.164: 93-147.

[91] Huggett, R.J., Kimerle, R.A., Mehrle Jr., P.M., Bergman, H.L., 1992. Biomarkers: Biochemical, Physiological, and Histological Markers of Anthropogenic Stress. Lewis, Boca Raton, FL. 
[92] Asensio, V., Rodríguez-Ruiz, A., Garmendia, L., Andre, J., Kille, P., Morgan, A.J., Soto, M., Marigómez, I., 2013. Towards an integrative soil health assessment strategy: a three tier (integrative biomarker response) approach with Eisenia fetida applied to soils subjected to chronic metal pollution. Sci. Total Environ. 442, 344-365.

[93] Irizar, A., Rivas, C., García-Velasco, N., Goñi de Cerio, F., Etxebarria, J., Marigómez, I., Soto, M., 2015a. Establishment of toxicity thresholds in subpopulations of coelomocytes (amoebocytes vs. eleocytes) of Eisenia fetida exposed in vitro to a variety of metals: implications for biomarker measurements. Ecotoxicol 24, 1004-1013.

[94] Scott-Fordsmand, J.J., Weeks, J.M. 2000. Biomarkers in earthworms. Rev. Environ. Contam. Toxicol. 165, 117-159.

[95] Sanchez-Hernandez, J. 2006. Earthworm biomarkers in ecological risk assessment. Reviews of environmental contamination and toxicology. 188. 85-126.

[96] Irizar, A., Rodríguez, M.P., Izquierdo, A., Cancio, I., Marigómez, I., Soto, M., 2015b. Effects of soil organic matter content on cadmium toxicity in Eisenia Fetida: implications for the use of biomarkers and standard toxicity tests. Arch. Environ. Contam. Toxicol. 68, 181-192.

[97] Asensio, V., Kille, P., Morgan, A.J., Soto, M., Marigómez, I., 2007. Metallothionein expression and Neutral Red uptake as biomarkers of metal exposure and effect in Eisenia fetida and Lumbricus terrestris. Eur J Soil Biol. 43, 233-238.

[98] Spurgeon, D.J., Lofts, S., Hankard ,P.K., Toal, M., McLellan, D., Fishwick, S., Svendsen, C., 2006. Effect of $\mathrm{pH}$ on metal speciation and resulting metal uptake and toxicity for earthworms. Environ. Toxicol. Chem. 25, 788-796.

[99] Li, M., Liu, Z., Xu, Y., Cui, Y., Li, D., Kong, Z., 2009. Comparative effects of $\mathrm{Cd}$ and $\mathrm{Pb}$ on biochemical response and DNA damage in the earthworm Eisenia fetida (Annelida, Olihochaeta). Chemosph. 74, 621-625.

[100] Zhang, Y., Shen, G., Yu, Y., Zhu, H., 2009. The hormetic effect of cadmium on the activity of antioxidant enzymes in the earthworm Eisenia fetida. Environ. Pollut. 157, 3064-3068.

[101] Berthelot, Y., Valton, É., Auroy, A., Trottier, B., Robidoux, P.Y., 2008. Integration of toxicological and chemical tools to assess the bio availability of metals and energetic compounds in contaminated soils. Chemosph. 74, 166177.

[102] Žaltauskaitè, J., Sodienè, I., 2014. Effects of cadmium and lead on the life cycle parameters of juvenile earthworm Eisenia fetida. Ecotoxicol. Environ. Saf. $103,9-16$.

[103] Fourie, F., Reinecke, S. A., Reinecke, A .J., 2007. The determination of earthworm species sensitivity differences to cadmium genotoxicity using the comet assay. Ecotoxicol. Environ. Saf. 67, 361-368.

[104] Liang, S.-H., Chen, A.-C., Chen, C.-Y., Kao, C.-M., Yang, J.-I., Shieh, B.-S., Chen, J.-H., Chen, C.-C., 2011. Cadmium-induced earthworm meta- 
llothionein-2 is associated with metal accumulation and counteracts oxidative stress. Pedobiolog. 54, 333-340.

[105] Wu, B., Liu, Z., Xu, Y., Li, D., Li, M., 2012. Combined toxicity of cadmium and lead on the earthworm Eisenia fetida (Annelida, Oligochaeta). Ecotoxicol. Environ. Saf. 81, 122-126.

[106] Hayashi, Y., Engelmann, P., Foldberg, R., Szabo, M., Pollak, E ... Heckmann, L.H. 2012. Earthworms and humans in vitro: Characterizing evolutionarily conserved stress and immune responses to silver nanoparticles. Environ Sci and Tech 46, 4166-4173.

[107] Cholewa-Waclaw, J., Feeney, G., O'Reilly, M., Stürzenbaum, S., Morgan, A., Płytycz, Barbara. 2006. Autofluorescence in eleocytes of some earthworm species. Folia histochemica et cytobiologica . Polish Academy of Sciences. Polish Histo. and Cytochem. Soc..44. 65-71.

[108] Cooper, E.L., Kauschke, E., Cossarizza, A., 2002. Digging for innate immunity since Darwin and Metchnikoff. Bio Eass 24, 319-333.

[109] Kurek, A., Homa, J., Kauschke, E., Plytycz, B., 2007. Characteristics of coelomocytes of the stubby earthworm, Allolobophora chlorotica (Sav.). Eur.j. Soil. Biol. 43,121-126.

[110] Hamed, S.S., Kauschke, E., Cooper, E.L .2002. Cytochemical properties of earthworm coelomocytes enriched by Percoll. In: A New Model for Analyzing Antimicrobial Peptides with Biomedical Applications. Beschin A, Bilej M, Cooper EL [Eds], IOS Press, Ohmsha, 29-37.

[111] Cooper, E.L., Stein EA .1981. Oligochaetes. In: Invertebrate Blood Cells. Ratcliffe NA, Rowley AF [Eds], Acad Press, , 75-140.

[112] Engelmann, P., Molnár, L., Pálinkás, L., Cooper, E.L., Németh, P., 2004. Earthworm leukocyte populations specifically harbour lysosomal enzymes that may respond to bacterial challenge. Cell Tissue Res 316, 391-401.

[113] Engelmann, P., Cooper, E.L., Németh, P., 2005. Anticipating innate immunity without a Toll. Mol. Imm. 42, 931-942.

[114] Adamowicz, A., 2005. Morphology and ultrastructure of the earthworm Dendrobaena veneta (Lumbricidae) coelomocytes. Tiss. Cell.37, 125-133.

[115] Affar, E.B., Dufor, M., Poirier, G.G., Nadeau, D .1998. Isolation, purification and partial characterization of chloragocytes from the earthworm species Lumbricus terrestris. Mol Cell Biochem .185 123-133.

[116] Peeters-Joris, C. 2000. The lysosomes of earthworm chloragocytes: biochemical and morphological characterization. Comp Biochem Physiol 126A: 323-340.

[117] Plytycz, B., Klimek, M., Klimek, B.A., Szymanski, W., Kruk, J., Morgan, A.J. 2011. Riboflavin content in the coelomocytes of contrasting earthworm species is differentially affected by edaphic variables including organic matter and metal content. Pedobiol. 54, 43-48.

[118] Moore, M.N., 1985. Cellular responses to pollutants. Mar Pollut Bull 16, 134-139. 
[119] Viarengo A., 1989. Heavy metals on marine invertebrates: mechanism of regulation and toxicity at the cellular level. Aquat Sci Review 1 (2), 295317.

[120] Spurgeon, D.J., Svendsen, C., Lister, L.J., Hankard, P.K., Kille, P. 2005. Earthworm responses to $\mathrm{Cd}$ and $\mathrm{Cu}$ under fluctuating environmental conditions: a comparison with results from laboratory exposures.Environ. Poll. 136, 3,443-452,0269-7491.

[121] Kaneshiro, E.S., Wyder. M.A., Cushion, M.T., 1993. Reliability of calcein acetoxy methyl ester and ethidium homodimer or propidium iodide for viability assessment of microbes. J Microbiol Meth 17(1), 1-16.

[122] Kwak, J., Kim, S.W, An, Y.J. 2014. A new and sensitive method for measuring in vivo and in vitro cytotoxicity in earthworm coelomocytes by flow cytometry. Environ Res 134, 118-126. 
